Portland State University

PDXScholar

\title{
Narratives of Marginalized Cyclists: Understanding Obstacles to Utilitarian Cycling Among Women and Minorities in Portland, OR
}

Amy Lubitow

Portland State University, alubitow@pdx.edu

Follow this and additional works at: https://pdxscholar.library.pdx.edu/trec_reports

Part of the Transportation Commons, Transportation Engineering Commons, Urban Studies Commons, and the Urban Studies and Planning Commons Let us know how access to this document benefits you.

\section{Recommended Citation}

Lubitow, Amy. Narratives of Marginalized Cyclists: Understanding Obstacles to Utilitarian Cycling Among Women and Minorities in Portland, OR. NITC-SS-994. Portland, OR: Transportation Research and Education Center (TREC), 2017. https://doi.org/10.15760/trec.171

This Report is brought to you for free and open access. It has been accepted for inclusion in TREC Final Reports by an authorized administrator of PDXScholar. Please contact us if we can make this document more accessible: pdxscholar@pdx.edu. 


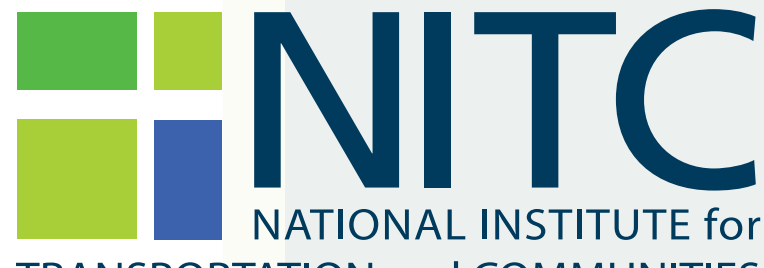

TRANSPORTATION and COMMUNITIES

FINAL REPORT

Narratives of Marginalized Cyclists:

Understanding Obstacles to Utilitarian Cycling Among Women and Minorities in Portland, OR

NITC-SS-994 May 2017

NITC is a U.S. Department of Transportation

national university transportation center.

HI! TREC 



\section{NARRATIVES OF MARGINALIZED CYCLISTS: UNDERSTANDING OBSTACLES TO UTILITARIAN CYCLING AMONG WOMEN AND MINORITIES IN PORTLAND, OR}

Final Report

NITC-SS-994

by

Amy Lubitow

Portland State University

for

National Institute for Transportation and Communities (NITC)

P.O. Box 751

Portland, OR 97207
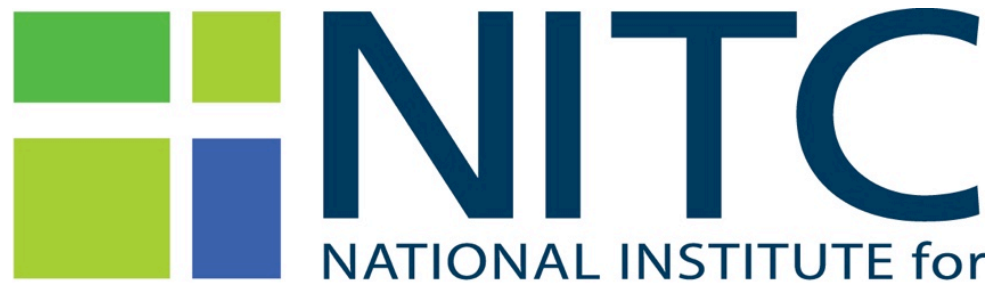

TRANSPORTATION and COMMUNITIES

May 2017 




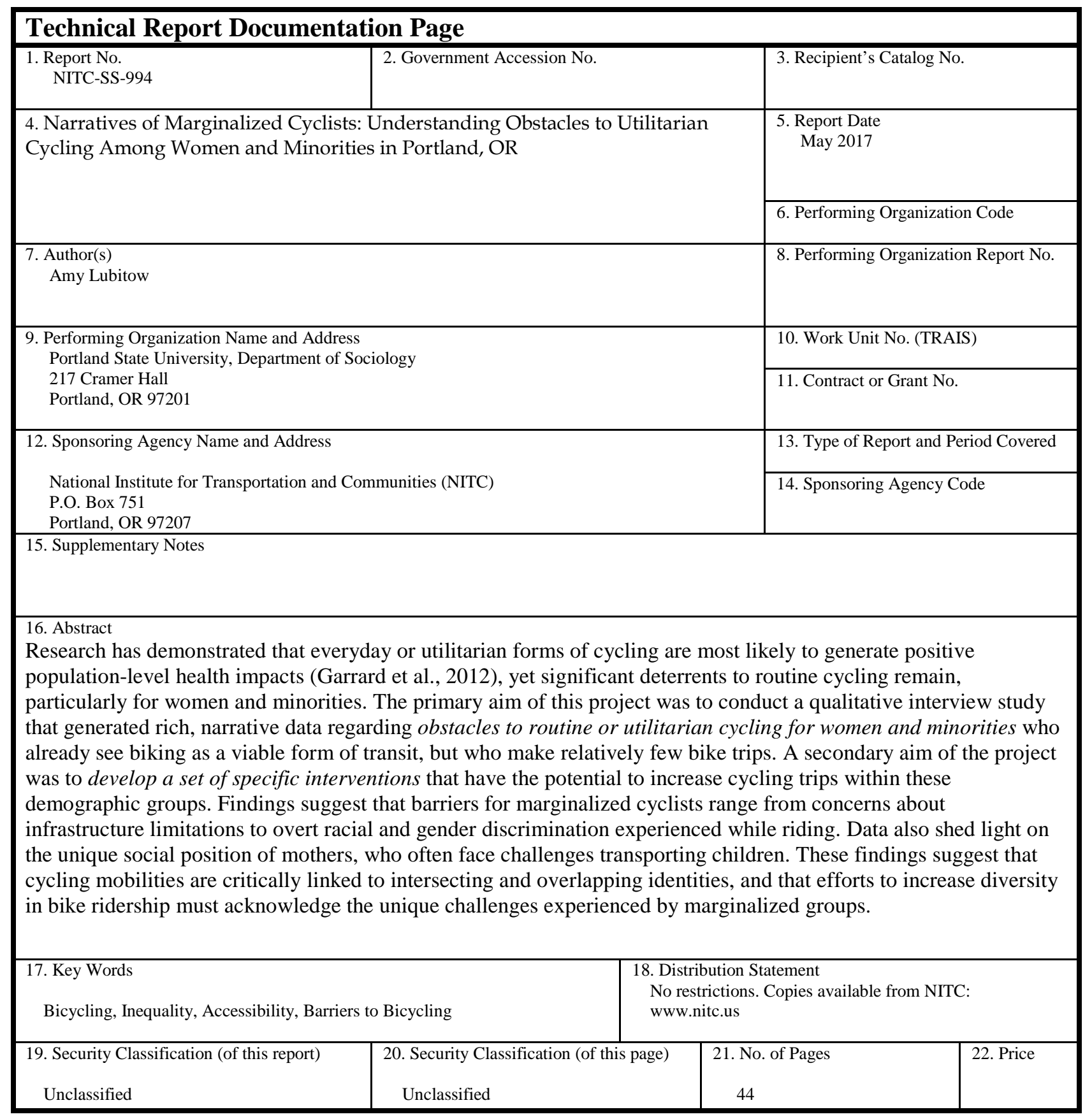





\section{ACKNOWLEDGEMENTS}

This project was funded by the National Institute for Transportation and Communities (NITC) and the Institute for Sustainable Solutions at Portland State University.

\section{DISCLAIMER}

The contents of this report reflect the views of the author, who is solely responsible for the facts and the accuracy of the material and information presented herein. This document is disseminated under the sponsorship of the U.S. Department of Transportation University Transportation Centers Program and the Portland State University Institute for Sustainable Solutions in the interest of information exchange. The U.S. Government assumes no liability for the contents or use thereof. The contents do not necessarily reflect the official views of the U.S. Government or Portland State University. This report does not constitute a standard, specification, or regulation.

\section{RECOMMENDED CITATION}

Lubitow, Amy. Narratives of Marginalized Cyclists: Understanding Obstacles to Utilitarian Cycling Among Women and Minorities in Portland, OR. NITC-SS-994. Portland, OR: Transportation Research and Education Center (TREC), 2017. 


\section{TABLE OF CONTENTS}

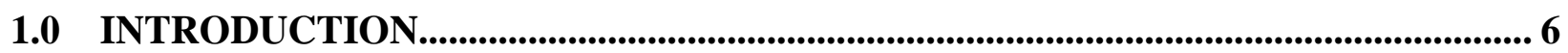

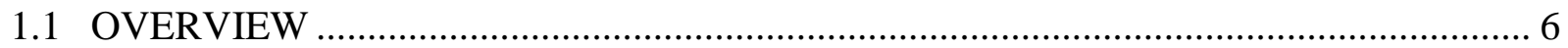

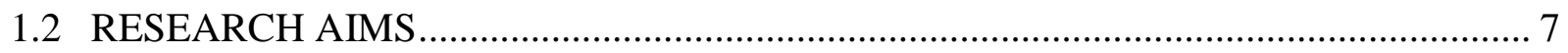

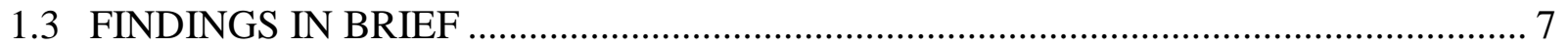

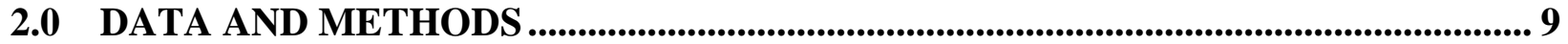

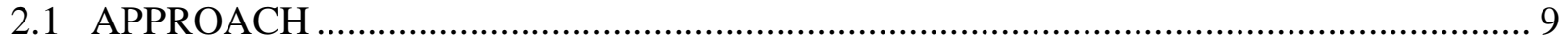

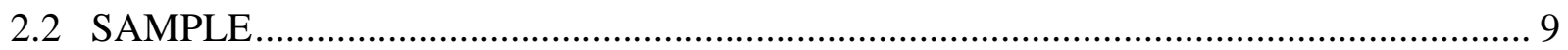

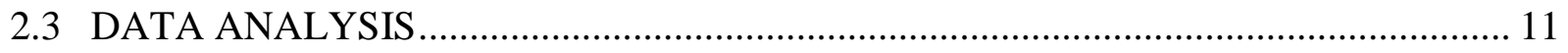

3.0 GENDERED BARRIERS TO ROUTINE CYCLING ............................................... 12

3.1 SAFETY, VISIBILITY AND HARASSMENT ………............................................ 12

3.1.1 Women's Perceptions of Safety While Biking ......................................................... 12

3.1.2 Increased Visibility and Gendered Harassment .......................................................... 13

3.2 GENDERED EXPECTATIONS FOR WOMEN'S APPEARANCE …………................ 14

3.3 PARENTING AND HOUSEHOLD LABOR AS A BARRIER TO BIKING ................... 15

3.4 INTERVENTIONS TO PROMOTE BICYCLING FOR WOMEN …………................. 16

4.0 RACE, ETHNICITY AND BARRIERS TO ROUTINE CYCLING.............................. 19

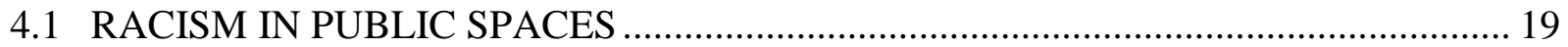

4.1.1 Police Violence Against People of Color ................................................................ 19

4.1.2 Microaggressions in Public Spaces..................................................................... 21

4.1.3 White Privilege ....................................................................................................... 22

4.2 WHITE CYCLING CULTURE AND (IN)VISIBILITY OF MINORITIES .................... 24

4.3 INTERVENTIONS TO INCREASE RIDERSHIP AMONGST PEOPLE OF COLOR . 27

5.0 INTERSECTING IDENTITIES: RACE, CLASS, GENDER, AGE \& ABILITY ...... 29

6.0 CONCLUSION: PROMOTONG ROUTINE CYCLING FOR WOMEN AND

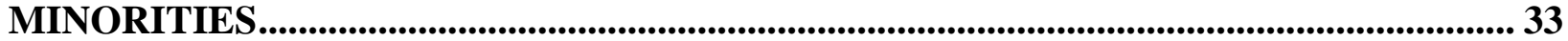

6.1 SO WHY BIKE? EMPOWERMENT AND FREEDOM.................................................. 33

7.0 REFERENCES................................................................................................................... 37

8.0 APPENDIX ............................................................................................................................ 41

8.1 INTERVIEW GUIDE ............................................................................................... 41

\section{LIST OF TABLES}

Table 2.1: Sample Characteristics. $10-11$

Table 3.1: Suggested Interventions Related to Gender.............................................................. 17

Table 4.1: Suggested Interventions Related to Race/Ethnicity................................................. 28

Table 6.1: Suggested Interventions................................................................................... 36 


\section{EXECUTIVE SUMMARY}

The health benefits of bicycling are well understood; numerous studies link increased cycling activity with improved health outcomes. ${ }^{1}$ Garrard et al. (2012) suggest that the cycling behavior most likely to generate broad, population-level health benefits is everyday routine cycling including running errands and taking other short trips. Despite these health benefits and new investment in cycling infrastructure, overall cycling levels in the U.S. lag behind many other nations. Amidst findings of increased ridership, research still finds that women and racial minorities are underrepresented as cyclists in the U.S. ${ }^{2}$ While quantitative data may reveal estimates of these disparities, we know little about the motivations or deterrents experienced by individuals. $^{3}$

This report draws from 28 in-depth interviews with women and minorities in Portland, OR, to clarify ongoing barriers to bicycling that prevent those who own a bike (and are thus not limited strictly by economic barriers) from becoming more routine cyclists. ${ }^{4}$

Findings suggest that barriers for marginalized cyclists range from concerns about infrastructure limitations to overt racial and gender discrimination experienced while riding. Data also shed light on the unique social position of mothers, who often face challenges transporting children. These findings suggest that cycling mobilities are critically linked to intersecting and overlapping identities, and that efforts to increase diversity in bike ridership must acknowledge the unique challenges experienced by marginalized groups.

\footnotetext{
${ }^{1}$ Garrard, Jan, Chris Rissel, and Adrian Bauman. 2012. “Health Benefits of Cycling.” In: John Pucher and Ralph Buehler (Editors), City Cycling. MIT Press, Cambridge, MA; Oja, Pekka, Sylvia Titze, Adrian Bauman, Bas de Geus, P. Krenn, B. Reger-Nash, and T. Kohlberger. 2011. "Health benefits of cycling: a systematic review." Scandinavian Journal of Medicine \& Science in Sports 21: 496-509.

${ }^{2}$ Buehler, Ralph and John Pucher. 2012. "International Overview: Cycling Trends in Western Europe, North America, and Australia; Garrard, Jan, Susan Handy, and Jennifer Dill. “Women and Cycling.” Both found in: John Pucher and Ralph Buehler (Editors), City Cycling. MIT Press, Cambridge, MA.

${ }^{3}$ Emond, Catherine, Wei Tang, and Susan Handy. 2009. "Explaining gender difference in bicycling behavior.” Transportation Research Record 2125(1): 16-25.

${ }^{4} 30$ interviews were conducted, but at the time of this report writing, two interviews had yet to be transcribed. Additional research and future publications will highlight similar themes from the full sample of 30 individuals.
} 


\subsection{INTRODUCTION}

\subsection{OVERVIEW}

The health benefits of bicycling are well researched and although methodologies and research sites may vary, numerous studies link increased cycling activity with improved physical and mental health outcomes (Garrard et al., 2012; Huy et al., 2008; Litman and Doherty, 2009; Oja et al., 2011; Pucher et al., 2010; Wen and Rissel, 2008). Notably, Garrard et al. suggest that the type of cycling behavior that is most likely to generate broad, population-level health benefits is cycling to and from places - including running errands, visiting friends or family, and taking other short trips. This utilitarian or habitual form of cycling has more direct health benefits across multiple demographic groups due to the routinization of physical activity that doesn't require investments in more traditional exercise routines.

Despite the demonstrated health benefits and ongoing public investment in cycling infrastructure, overall cycling levels in the U.S. lag behind many other industrialized nations (Buehler and Pucher, 2012). Amidst promising findings of overall increases in bike trips in the U.S., research consistently finds that significant barriers remain (Buechler and Pucher, 2012; Garrard et al., 2012a). Barriers to bicycling appear to be particularly acute for women, who continue to take significantly fewer trips by bike than men (Aldred et al., 2015; Bopp et al., 2014; Emond et al., 2009; Garrard et al., 2008; 2012a), and racial and ethnic minorities, who make up a fast-growing segment of U.S bicyclists but, in urban areas, are increasingly at risk of displacement to suburban areas where mobility and active transportation choices are more limited (McKenzie, 2013).

Although both scholars and community organizations have begun the critically important task of exploring the specific barriers to bicycling for women and minorities, much of this work utilizes quantitative methodologies to ascertain barriers across multiple groups (Bopp et al., 2014; Dill and McNeil, 2013; Emond et al., 2009; Garrard et al., 2012a; Pucher et al., 2011).

While recent research has been conducted on cycling patterns and behaviors for different demographic groups (Pucher et al., 2011), and there is an increasingly robust dialogue on women and cycling (Emond et al.,; Garrard et al, 2008, 2012a; Steinbach et al., 2011), there remains a dearth of both qualitative work and a more focused emphasis on racial and ethnic minority cycling behaviors. The current study seeks to build upon existing research to clarify what strategies prevent women and minorities (specifically those who own a bike and are comfortable with riding it) from becoming more routine cyclists. Though a number of research studies have explored the specific types of interventions that might increase overall bike ridership (see Pucher, Dill and Handy, 2010 for discussion), little research has explored the unique vulnerabilities that women and minorities may experience.

A note on language: The term minorities is specifically used in this study to refer to all nonwhite persons who participated in this research. While persons or people of color are also appropriate terms, the use of "minorities" is particularly useful to highlight the small proportion of people of color in Oregon and the city of Portland specifically. 
The term "marginalized" is used throughout this study to describe the experiences of both women and minority cyclists' experiences in Portland. These groups are referred to as marginalized for two reasons: 1) Historically both women and minorities have been considered marginalized groups due to ongoing structural inequalities related to race and gender that limit access to opportunities and resources and also limit free movement within public spaces; 2) Rates of cycling amongst women and minorities remain relatively low as compared to white men, making these groups more marginalized within the practice of bicycling in the United States.

\subsection{RESEARCH AIMS}

The primary purpose of this research is to understand the obstacles to regular (or utilitarian) cycling amongst women and minority bicyclists in Portland. Specific research questions include:

Obstacles to utilitarian cycling 5 : For women and minority bike riders who make at least one trip via bike per month, what physical, social, economic, safety or other concerns prevent them from taking additional bike trips of any type?

Interventions to increase utilitarian cycling: For women and minority bike riders who make at least one trip via bike per month, what specific social, cultural, infrastructural or other changes would encourage them to take at least one additional trip on their bike each month? Additionally, what factors encourage riders to use their bike that could be expanded upon or further improved?

\subsection{FINDINGS IN BRIEF}

In general, women and minorities in this study described a range of challenges incorporating cycling into their everyday routines. Some challenges were linked to concerns or experiences with sexism and racism in public spaces, while other were linked to concerns about safety in relation to infrastructure or a lack of time or gear to make cycling accessible. In this report, the concepts that emerged as consistent challenges to women and minorities are explored in more depth, with suggested interventions to address these issues discussed in each chapter.

\footnotetext{
${ }^{5}$ A note on language: In some instances "routine" is used as a synonym for utilitarian. That word had more traction with participants and was the way most participants referred to cycling behaviors that included an increase in the volume of trips.
} 



\subsection{DATA AND METHODS}

\subsection{APPROACH}

Thirty qualitative interviews were conducted with adult women and racial or ethnic minorities who are 18 years or older and live and bike in the Portland metro area. ${ }^{6}$ The Portland area is an ideal location for this project because it is one of the most "bike-oriented cities" in the U.S. (Pucher and Buehler, 2012), therefore increasing the likelihood of identifying participants in the target population. Interviews lasted 45 minutes to over two hours, and were audio recorded and professionally transcribed. Interviews were conducted in English (outreach efforts were made to accommodate alternative language preferences).

\subsection{SAMPLE}

In order to participate, participants had to meet the following criteria.

18 years or older

Must live in the Portland metro area

Must self-identify as a woman or as a racial/ethnic minority (or both)

Must self-report that they ride a bike at least once a month, but are not a frequent (more than once per week) bike commuter ${ }^{7}$

Purposive sampling was used to recruit participants who met the above sample criteria.

Recruitment of participants in the targeted demographic groups was achieved by a) Posting fliers or recruitment language on approximately 20 public Facebook pages that are typically followed by women or minorities (e.g.. the Portland Major Taylor Cycling Club page); b) Snowball sampling from participants who agreed to be interviewed; and c) Making announcements at public meetings that were oriented around issues of cycling or public safety in Portland.

To ensure a diverse sample, all potential interviewees were asked to complete a very brief, confidential, demographic screening questionnaire before an interview was scheduled. For those participants recruited via online mechanisms, a link to a confidential survey was provided. For those who learned about the study from another interviewee, the potential participant was emailed a link to the online version of the screening tool. The screening questionnaire asked

\footnotetext{
${ }^{6} 30$ interviews were conducted, though only 28 interviews have been fully transcribed. Therefore, the findings presented here only draw from the content of the first 28 interviews. The final two interviews were similar in nature to the first 28 interviews and would not in any invalidate the findings presented here. In future publications, the full sample will be used in its entirety.

${ }^{7}$ Dill and McNeil (2013) characterize utilitarian cyclists as "cyclists who had cycled at least once in the past 30 days for transportation and usually cycled at least once a month for transportation in a typical summer or winter month" (p.2387). For the purposes of this study, we hope to use this as a baseline for "potential utilitarian cyclists" to be recruited. The proposed research is thus focused on the specific riders who see their bike as a viable form of transit, but do not commute via bike. The rationale for this approach is to seek out participants who might otherwise broaden their cycling habits, but do not because specific barriers remain.
} 
participants to provide information about their gender, race or ethnicity, their cycling activity, and their educational level (as a loose proxy for social class). The screening questionnaire ensured that both women and racial/ethnic minorities were well represented in the sample; this approach to generating a diverse sample is particularly important in Portland given the relatively low percentage of racial and ethnic minority residents.

At the start of the interview all participants were given a short demographic questionnaire that asked questions about their background and identity. This data was collected in order to clarify which issues were more prevalent or important for particular groups. All participants were given a pseudonym.

In brief, the sample of 28 presented in this report included 18 people of color, 21 women, four men and three people who identified as queer/genderqueer or transgender/gender nonconforming. ${ }^{8}$ Most participants were between the ages of 25 and 44 (though two were under 25 and seven were over 44). Nine participants were parents and all participants identified as “infrequently" riding a bike - meaning they reported riding more than once a month, but fewer than 10 times a month.

Table 2.1. Sample Characteristics

\begin{tabular}{|c|c|c|c|c|c|}
\hline Pseudonym & Employment & Age & Gender & Race & Education \\
\hline Janet & Part-time & 43 & Female & White & Some college \\
\hline Margaret & $\begin{array}{l}\text { Part-time } \\
\text { (two jobs) }\end{array}$ & 27 & Female & White & Graduate degree \\
\hline Jade & Full-time & 38 & Female & White & Bachelor's degree \\
\hline Elizabeth & Part-time & 60 & Female & White & Graduate degree \\
\hline Mary & Unemployed & 57 & Female & White & Graduate degree \\
\hline Julia & Full-time & 39 & $\begin{array}{c}\text { Femme } \\
\text { Genderqueer }\end{array}$ & White & Graduate degree \\
\hline Robin & Full-time & 55 & Female & $\begin{array}{c}\text { Multiple: Black/African } \\
\text { American, Hispanic or } \\
\text { Latino }\end{array}$ & Graduate degree \\
\hline Rosa & Part-time & 22 & Female & $\begin{array}{c}\text { Multiple: } \\
\text { Hispanic/Latino, White, } \\
\text { Mixed }\end{array}$ & Some college \\
\hline Katie & Full-time & 28 & Female & White & $\begin{array}{l}\text { High-school } \\
\text { graduate/GED }\end{array}$ \\
\hline Velia & Full-time & 36 & Female & Hispanic/Latina & Bachelor's degree \\
\hline Evelyn & Full-time & 42 & Female & White & Bachelor's degree \\
\hline Peter & Full-time & 45 & Male & Black/African American & Some college \\
\hline Manuela & Full-time & 31 & Female & Hispanic/Latina & Bachelor's degree \\
\hline
\end{tabular}

\footnotetext{
${ }^{8}$ The final two participants to be included in additional papers and reports identified as men of color. No white men were included in this sample given the research focus on women and minorities.
} 


\begin{tabular}{|c|c|c|c|c|c|}
\hline Jordan & Part-time & 29 & $\begin{array}{c}\text { Female } \\
\text { Genderqueer }\end{array}$ & $\begin{array}{c}\text { Multiple: Hispanic or } \\
\text { Latino, Black/African } \\
\text { American, Alaskan } \\
\text { Native or American } \\
\text { Indian }\end{array}$ & Some college \\
\hline Miguel & Full-time & 29 & Male & Hispanic/Latino & Some college \\
\hline Ana & Full-time & 30 & Female & Hispanic/Latina & Graduate degree \\
\hline Nicole & Full-time & 26 & Female & White & Bachelor's degree \\
\hline Carol & Part-time & 42 & Female & Latina/White & Bachelor's degree \\
\hline Angela & Full-time & 36 & Female & White & $\begin{array}{c}\text { Trade/vocational/tech } \\
\text { nical training }\end{array}$ \\
\hline Carla & Yes & 28 & Female & $\begin{array}{c}\text { Multiple: Black/African } \\
\text { American, Hispanic or } \\
\text { Latino }\end{array}$ & Some college \\
\hline Simone & Full-time & 45 & Female & $\begin{array}{c}\text { Multiple: Black/African } \\
\text { American, Alaskan } \\
\text { Native or American } \\
\text { Indian }\end{array}$ & $\begin{array}{c}\text { Trade/vocational/tech } \\
\text { nical training }\end{array}$ \\
\hline Janae & Full-time & 46 & Female & Black/African American & Associate Degree \\
\hline Tara & $\begin{array}{l}\text { Part-time } \\
\text { (unpaid) }\end{array}$ & 32 & Female & American Indian & Associate Degree \\
\hline Helen & Part-time & 31 & Female & Black/African American & Bachelor's degree \\
\hline Aneisha & Full-time & 47 & Female & Black/African American & Graduate degree \\
\hline Marcus & Full-time & 40 & Male & Black/African American & Associate Degree \\
\hline Demetrius & Part-time & 19 & Trans Male & Black/African American & Some college \\
\hline Samuel & Full-time & 27 & Male & Hispanic/Latino & Bachelor's degree \\
\hline
\end{tabular}

\subsection{DATA ANALYSIS}

Interviews were analyzed using a multistep process of constant comparison (Glaser and Strauss, 1967; Strauss and Corbin, 1999). As part of the data analysis process, conceptual categories were developed regarding reported obstacles to cycling (Bogdan and Biklen, 2007). This process was conducted as follows: 1) Review and assess the interview transcripts for common concepts or themes independently; 2) Compare the thematic elements developed and search for overlap and commonality; 3) Use the Dedoose qualitative data analysis program to code data into thematic categories; and 4) Reread transcripts, comparing observations regarding trends in the data to confirm or disconfirm trends that emerged. 


\subsection{GENDERED BARRIERS TO ROUTINE CYCLING}

Twenty-three of the 28 participants whose interviews are included in this research report were women; 10 participants identified as white and the other 13 participants identified as a racial/ethnic minority. Two participants identified as female and genderqueer, meaning that their primary gender identity was female but that they experienced their gender in a more fluid way. In this chapter, findings are presented that center on how one's gender impacts the experience of biking. Specific concerns center on issues of safety and harassment, challenges facing mothers, and additional pressures related to gender and appearance that factor into participants' desire or ability to bike.

\subsection{SAFETY, VISIBILITY AND HARASSMENT}

For women in this study, riding a bike could oscillate between being empowering in one moment and stressful or frightening in the next. Women reported feeling simultaneously visible and invisible on their bikes. On one hand, they might experience a sense of agency with the speed that a bike provides for escaping perceived or blatant threats, while on the other hand they often reporting feelings of anxiety and fear due to the fact that, as a woman on a bike, they were noticeable in public spaces.

\subsubsection{Women's Perceptions of Safety While Biking}

Respondents related their cautious feelings to their identity as a woman, and the risks associated with the inherent nature of being a woman in a public space. Carol, a Latina woman, used the metaphor of a woman's mental "map" to highlight what most women participants felt about avoiding cycling in certain areas:

I think on a bicycle I would be a little bit more cautious. I would go to bars maybe [in] the Central Eastside, but I wouldn't want to come downtown because stuff can get kind of sketchy... I think bicycling at night I'd have to turn on that female sense of like, there's a map of the city and then there's a lady's map of the city, which is like you shouldn't go...there at night. And maybe why I choose to drive is because it's being able to say I don't have to pay attention to that. I can go where I want.

Some women noted how broader fears of violence against women will impact when and where they travel. Women respondents often discussed additional precautions they might take after dark (such as riding with friends, taking well-lit or more populated routes, or avoiding travel altogether in certain areas).

Evelyn reflected on how her friend's experience of violence while biking had informed her own biking habits:

I had a friend, a couple years ago who was riding her bike...on like 12th and Morrison... she was riding her bike home from work one night and some dude just like knocked her off her bike and beat her up... That could happen anywhere ... Her experience kind of stuck with me. So definitely, like, I know when I have been alone and riding my bike, I do definitely keep my eye out... like, “Oh, there's a guy four blocks ahead at the bus 
stop. And he's kind of edging towards the street as I get closer.” Like, I watch that, for sure. Because ...I don't know what might happen... even in the daytime and even on busier streets... So I think it's definitely something that is always in the back of my mind. But I think that's probably true of being a woman anywhere, doing anything.

Helen sums up the feelings of a number of women in the study who felt that, as women riding bicycles, there was an additional burden of being aware of both your physical surroundings, but also the social environment:

In the times when I have biked with my spouse, [he's] always like, "Can we chill?” ... and I'm like, "No, this is way that people bike. They like, go...you have to bring it." As a female, I would say that...I feel more defensive and a little bit more vulnerable...you want to have your, like, "I'm-unfuckable-with" vibe going on...And that would be the same if I was walking. That's just females being out. It's in your interest to be...not to let anybody think that you're not ready for them.

Robin, in reflecting upon some of the challenges and fears women may face in deciding to bike, shared her idea for a "bike buddy" program:

I applied for a job at a company once where...here in Portland, where they would come and send a [public transit] buddy on your first day of work. One [employee] would come by your house and show you the bus route to get downtown... at least for me, I would love to have a bicycle buddy. And I would love to have a female bicycle buddy that would say, "Oh, there's this great trench coat I found [to bike in]" you know, or...you know, try this cape. This is really cool.” Or let’s just go together. Because we can do it together.

Overall, women in this study reported a reluctance to bike due to larger social and cultural dynamics that make bicycling an experience that could be fraught with anxiety or stress, and an additional sense of increased awareness of their surroundings when biking.

\subsubsection{Increased Visibility and Gendered Harassment}

In addition to women worrying about where they ride their bikes, women spoke repeatedly about their increased visibility while biking. For many women, because fewer women tend to ride bikes compared to men, being a woman on a bike might draw additional attention from men in cars or on sidewalks. Women reported finding that biking routinely elicited catcalls and other forms of harassment from men.

Margaret, a white woman, recounted one of the more vivid scenarios of harassment from this study, which could have resulted in an injury or accident:

One particular time, and this has happened many times, but this was one where I actually felt a little bit scared, like I might get run off of the road... a friend and I were riding up North Denver Avenue and these guys passed us once, I think, and then we came up to a stoplight, and then they started revving up and they passed us again. And as they passed, they were like "I wanna grab your ass! I wanna grab your ass!” and they were leaning out of the window as we were biking up Denver right as [the road] starts getting really 
narrow there... And I was like, “Oh my god, I'm going to get smashed into the parked cars over here.”

Less extreme were the sort of "everyday" interactions that women experienced while bicycling. Tara, for example, noted that she experienced street harassment or catcalling:

At least once every two times I ride my bike [I am harassed]. Even people in cars are like, "Hey, hey there girl!" or I'll ride through a crowd of guys, like even two or three guys, and they're like "Hey!” it's just like... ugh. Just once I want to ride through a crowd of people and be ignored. Or be invisible.

Katie reflected on what it means to be a woman riding a bike and noted the range of negative experiences she'd had:

I've had a lot of inappropriate experiences with drivers. Guys get really excited when there's a girl [biking]... I've had a lot of experiences where it's not just like catcalling or yelling out the window (but there is a lot of that), and...I'm wearing yoga pants and a tight shirt or a sports bra or something. And I'm constantly told how my ass looks, and people slowing down trying to have a conversation, getting cut off the road because someone thinks it's fun to make me feel more anxious. I've had a lot of that happen.

Like Katie, Velia indicated that she had been harassed while riding her bike, often based on her clothing choices:

I wear whatever I want when I'm riding a bike. But that also comes with people looking at you or making comments because it's hot [warm outside] and I'm wearing short shorts and I'm riding a bike. Or I'm wearing a tank top and I'm on a bike. I'm more visible because I am a woman on a bike.

Sexual harassment, catcalling and other forms of street harassment have been discussed to some degree in academic literature (Tran, 2015; Tuerkheimer, 1997). Activist efforts to counteract some of these harmful cultural patterns have led to the emergence of a range of bystander intervention trainings and programs which, if deployed broadly to public officials and public employees, might help to offset some of the negative public harassment that is occurring (Vidu, Valls, Puigvert et al., 2017).

Finally, it should be noted that the intersections of race and gender are important here. Many participants in this study reported that their racial or ethnic identity impacted how they experienced and thought about bicycling. In Section 4, experiences of racism in relation to biking will be discussed.

\subsection{GENDERED EXPECTATIONS FOR WOMEN'S APPEARANCE}

When asked in interviews about things that made it more challenging to bike, women in this study consistently mentioned how physical appearance and external pressures to look a certain way upon arrival at a destination often deterred them from riding. This was most frequently mentioned in relation to biking to work. 
Angela, for example, noted varied expectations about women's and men's appearances in the workplace and how her concerns about self-presentation meant that she did not find bike commuting to her work in the field of healthcare to be viable:

I have male coworkers that ride to work, and they show up and they're just gross... And they wipe off with a towel, and they put on their scrubs, and it's not a problem. But if I were to show up to work in the same condition that they showed up to work, and wipe off with a towel, and just put on my scrubs, I'd get looked at funny. There's a different expectation for how you present yourself at work...Just feeling like you have to get there in a way that you can still present yourself when you show up...

Carol noted that, although her current job did not have as much of an emphasis on a particular dress code, it would potentially impact her future choices: "If I worked somewhere with a very feminine dress code then I would skip the bicycle and just take public transit.” Expressing a similar sentiment, Carla reported that it takes extra effort for her to consider how what she's wearing matches up with the desire to bike:

That's probably one thing that male cyclists don't think about versus female cyclists. I mean, you have to wear shorts. If you're wearing pants then you'd probably cycle in them...it's that added thing of, "Is my dress too short? Do I need to put on some bike shorts? Do I need to put that pencil skirt away?” because you can’t bike in a pencil skirt...

Robin reflected on her experiences of not having proper clothing to wear to commute, as well as the impact of wearing a helmet on the appearance of one's hair. She offered this:

Part of it, I think, is like I don't have the right clothes to wear or my helmet hair. I don’t really care about helmet hair. I kind of have helmet hair every day. I don't really care that much about my hair, whereas other Black women might... [but] how do I dress professionally and get to work, and how do I want to look during the day?

Many women, and some men, in this study reported that they often chose other forms of transportation over bicycling due to expectations about their physical appearance in the workplace. In some ways, these pressures may be linked to broader cultural expectations and pressures about one's physical appearance. However, solutions to this issue need not be exclusively social/cultural fixes. Increasing the availability of lockers and access to showers or changing rooms for workers would help to reduce some of challenges workers face in making the choice to bike to work (as confirmed by Buehler, 2012). The notion of a "bike buddy" to help riders become comfortable biking longer distances might also help to inspire more women to bike.

\subsection{PARENTING AND HOUSEHOLD LABOR AS A BARRIER TO BIKING}

Nine of the 28 participants in this study were parents to, or had previously parented, young children. For women, being a parent created challenges in biking how and where they wished to 
bike. These participants often had the most difficulty finding time to use their bicycle whether for utility or recreation given competing demands on their time, energy, and their frequent need to make multiple stops for child-related or household work such as grocery shopping.

Evelyn, a mother to a grade-schooler, reflected on losing opportunities to cycle after having her first child. She talked about having to use the family car to take care of their son, while her husband commuted to and from work by bicycle. She saw this transformation of her cycling habits as a feminist issue:

This is totally a feminist issue and why... women don't ride bikes as much. Because we are, very often, the ones who are responsible for childcare and child pickup and grocery shopping, which is more difficult to do for a family on a bike... I don't see [biking] as an option for me as much anymore because of having to pick up kids from school, and having to be responsible for the grocery shopping... there's just not enough time to do any of that stuff. And especially if I'm going to take the time to ride my bike to do it.

Similarly, Janet, a single mother, assumes all responsibility for managing her and her child's time, and pointed out the physical difficulties of child rearing while bicycling:

I commuted downtown almost every day in all of my 20s... the fact of being a mother... and always having to schlep all that stuff around... it makes it not fun....[and] it's a timing thing. If it's past a certain time, I don't have time to ride my bike to work, I have to get in the car. I might have intentions like I'm going to ride my bike tomorrow and get everything ready, and then the morning gets away from me and I don't have time to ride my bike.

Aneisha, a mother of two boys aged 11 and 12, reflected on the fact that her boys could now join her and her husband on casual rides, but that being a mom meant that she had to carve out time for faster or longer rides (which she had just begun doing in a cycling group for women). She also noted that she still had yet to graduate from her "mommy bicycle" that was heavier and able to carry more things to what she called an "adult bike" that would be easier and faster to ride.

In relation to children, interventions to promote more ridership amongst mothers might focus around increased events and opportunities to bike for recreation alongside children; classes or opportunities to learn to adapt a bike to carry heavier loads or children (or in Aneisha's case above to transform a utility bike into a longer-distance bike); and enhanced infrastructure to better accommodate bike trailers and parents with children.

\subsection{INTERVENTIONS TO PROMOTE BICYCLING FOR WOMEN}

In this study women reported a range of obstacles to their feeling safe and secure when riding a bike. With concerns about and experiences with street harassment and fear of physical violence in certain places or at certain times, women consistently noted that when they bike they consider both the physical environment (the route, the bike lane) but are also in positions to have to consider the social environment (who is watching them as they bike? what social obstacles might they need to confront? how do they appear to others? Is this safe for them or their children if they're biking together?). In sum, some of the primary barriers to women taking up more routine cycling are complex social dynamics related to gender inequality. 
While some measures such as showers, bike lockers and changing rooms might help to encourage some women to bike to work, it is likely that the most critical changes must take place at a social and cultural level. Bystander intervention trainings to reduce street harassment as well as increasing opportunities for women to build confidence biking would be useful (e.g., women's bike clubs and riding groups; events for families; training classes to empower women to repair and adapt their bikes as needed).

Finally, it must be noted that women in this sample were asked about their "perfect ride." For nearly all participants that ride involved fast, direct travel with few interventions from outsiders, on lanes that were set apart from motorists and not too congested with cyclists. This composite "ideal ride" is in keeping with existing literature that speaks to the benefit of protected or isolated lanes in increasing overall bike ridership (Pucher, Dill and Handy, 2010)

Table 3. 1 Suggested Interventions Related to Gender

Public events that cater to parents and children

Training and support to adapt bicycles to meet the needs of parents

Bike lanes that better support parents cycling with trailers - wider, better lit, smoother transitions between areas

Additional showers or changing rooms

Bike buddy programs to support riders or additional women’s biking groups

Bystander intervention trainings to offset sexual and street harassment 



\subsection{RACE, ETHNICITY AND BARRIERS TO ROUTINE CYCLING}

Of 28 participants included in this report, 18 identified as a racial or ethnic minority. Of those 18 individuals, many reported concerns regarding systemic forms of racism. These issues ranged from concerns about police violence to challenges in maneuvering through public spaces that were not welcoming to people of color. These fears were more pronounced for AfricanAmerican interviewees, particularly concerns regarding policing and the attitudes of motorists or other cyclists.

Echoing the findings of the previous section in relation to gender, many people of color in this study reported a heightened sense of visibility when cycling. They routinely felt that, because they defied the stereotype of a white male cyclist, that they were more subject to increased surveillance (from law enforcement, but also from pedestrians, motorists and other bikers) when biking. In this section, the self-reported racial background of the interviewee is provided for context.

\subsection{RACISM IN PUBLIC SPACES}

\subsubsection{Police Violence Against People of Color}

Participants in this study were asked specifically to reflect on the degree to which parts of their identity impacted their experiences biking, or the degree to which they considering riding a bike. For African-American men and women, recent events regarding police violence significantly impacted their decisions about how and when to ride a bike - though concerns about police were common amongst minority respondents.

Janae, an African-American woman, discussed her concerns at great length. An abridged and shortened version of some of her thoughts demonstrate the significance of police violence in restricting the movement and mobility of people of color:

Janae: I don’t ride at night because of police officers, and possibly getting stopped, and possibly getting shot, so, that's really the bottom line to be honest. Not just the rush hour traffic, but the racial profiling.

Interviewer: Do you feel safe while cycling?

Janae: No.

I: No, ever?

Jenae: I do sometimes, but I know when police pass me, I immediately make sure, I just see myself doing inventory: I’ve got my lights, got my helmet, everything's to where they 
can't find a reason to pull me over. And I've even been stopped and asked if my bike was stolen because it's a high-end bike...

Janae went on to speak about how she felt both unsafe when biking, and also more aware and alert regarding the people around her:

I feel that being African American, I am more hyper vigilant. I am more fearful than a typical Caucasian person could be on the same bike, in the same neighborhood, at the same time. I have these layers of oppression, if you will, to have to worry about that never crosses a Caucasian person's mind...Unlike myself, you know, I'm thinking I am aware of my color, and of my culture, and my being an African-American woman at all times. I have to be aware of my surroundings. And it's, man, having all of these awarenesses and it does interrupt my experience. I can't really enjoy my experience as much as a typical person would because of all of the oppression that comes with riding a bike as an African American in our community.

Marcus, an African-American man, reported that the public visibility of police violence against African Americans in recent years had impacted his desire to bike:

Interviewer: When do you not feel safe?

Marcus: I think I don't feel safe if it were something crazy happens in the news that, like, elevates racial tension. That's when I feel, like, the least safe, you know.

Interviewer: Does it stop you from biking?

Marcus: It did, yeah. The recent shootings, like I stopped for awhile. Yeah.

Interviewer: What made you go back to biking?

Marcus: I think once everything had kind of calmed down and people focused their attention on other things, you know. Then I felt okay, I guess.

Miguel, a Latino man, reiterated Janae's point above that moving through space as a visible minority requires additional thought and restraint over one's movement. Though his comments are not expressly about fear of police violence, the concern over physical safety reflects dynamics of racialized violence targeting communities of color in the U.S.:

...People who [are] not White experience so much in their bodies, in their physical safety, and we [as minorities] learn at a really young age to not make our lives more in danger than they already are. I think that's something that we learn really, really early. So how do we respect that, right? ... there's not enough folks of color biking. And I think there's many reasons. Economically might be one, right? But also like vulnerability, right? This vulnerability that we have of our own physical safety. 
People of color reported feeling anxiety in relation to biking in public spaces. As a result, some individuals reported curbing their cycling habits. Interventions to address systemic racism and violence against minorities do not have easy answers. Reforms to policing practices and policies are critical in increasing feelings of safety and security for people of color.

\subsubsection{Microaggressions in Public Spaces}

For many minorities who participated in this research, smaller and subtler forms of racism (called microaggressions) had an impact on their cycling habits. Many respondents reported feeling aggressive behaviors from motorists or other cyclists that they felt were racially motivated.

Jordan, who identified as mixed race, reported experiencing microaggressions while cycling in a way that she connected to broader legacies of racism:

It's one thing to be a woman. It's another thing to be, like, a woman of color, like, in this town. Because this city... the KKK definitely ran supreme in Portland for a fucking long time. And it's what we have to organize against today... [and] the city is, like, low-key undertone with it. Since I've been in Portland, I've experienced a ton of microaggressions and especially with cycling. Like I said, you have, like, bike snobs that only want to talk down or try to explain or upsale or just make me feel as if I'm not so...I'm, like, not on their level.

Robin, an African-American woman, reflected on her experience of microaggressions in which motorists did not allow enough stopping distance for minority cyclists and pedestrians. ${ }^{9}$ She noted that she felt unsafe riding her bike in her own neighborhood:

What I know about who stops for whom, in crosswalks, is that people that are African American don't get stopped for. It scares me to be in the bike lanes here in Portland...I don't go in the bike lanes in my own neighborhood that I was born into, that I live in now, that I'm raising kids in. I don't go. And that's sad.

Marcus, an African-American man, began discussing what he called "road rage" in relation to his experiences of biking near car traffic. Like Robin, he noted that he had observed disparities in motorists' treatment of him as a person of color:

I do feel like being a minority in Portland, like, I've noticed that motorists are less likely to stop for you...if you're at, like, a crosswalk, even if you have the right of way. Which I do. You always have the right away if you're a cyclist or you're a pedestrian. ....And the reason I say that is because I've been at a stop before [on my bike] and just waiting for people to stop. And then like someone... [chuckles] you know, a White person will pull up next to me. And then all of a sudden, you know, traffic stops.

\footnotetext{
${ }^{9}$ A 2014 report by Goddard, Kahn and Adkins confirmed that "minority pedestrians experience discriminatory treatment by drivers" (2).
} 
Janae, an African-American woman, characterized microaggression on the bike as intentional aggression from other cyclists who didn't want to share the road. She clarifies that the intersections of race and class may be at play here as well:

I've had people ride so close to me, and then zip around me really quick, as if to intentionally and deliberately cause me discomfort or to scare me...I've had riders just so close to me, you know, just not being mindful of the rules of the road and giving me proper space, you know, pacing themselves behind me, but just aggressive riding, in my area. You know, just too close to me, to make me feel uncomfortable and I thought that was intentional. Cut me off. Because as I shared, when I first started biking I was pretty poor, I couldn't afford a nice bike so it couldn't get up the hills as quick as others and because I wasn't going fast enough they'd zip around me and then cut me off almost as to cause me to wreck because I wasn't moving fast enough, or keeping up with the pace of the people. So yeah, that was a deterrent, too.

In each of these examples, and the others like them that respondents in this study reported, aggressive driving on the part of motorists and cyclists was reported as a barrier to regular cycling. Minority participants in this study felt that white drivers and bikers treated them differently than they might treat white cyclists, and often felt that the lack of attention to people of color in crosswalks or at stop signs was racially motivated. Regardless of whether the intentions of white drivers or bikers in these examples were racially motivated, people of color experience these actions as racially motivated and therefore suffer psychological and social harm. Racism and racial inequality are embedded into the social fabric of the U.S. and, as such, routine interactions in public spaces can be fraught with tension.

Interventions to address microaggressions in public spaces are complex. Though racial bias training and education programs may help to reduce some of these issues, additional efforts to create safe and protected bike lanes, increase lighting and signage at heavily trafficked intersections, and increase the overall numbers of minorities who ride bikes can help to create safer, more equitable streets.

\subsubsection{White Privilege}

An important addition to the findings in the above section is that, when asked about how their race or ethnicity informed their cycling habits, white women consistently responded that they rarely, if ever, thought about their own racial identity in relation to their cycling behaviors. This is illustrative of how white privilege can function on the individual level. Those women who identified as white did not have to think about the specific ways that they might be treated differently by law enforcement, nor have to consistently reaffirm that they were following all of the rules of the road as they biked. This relative freedom of movement (despite the ways that gender may constrain their biking habits) demonstrates how racial privilege can appear normal, natural and invisible. This contrasts starkly with the experiences of minorities described above.

Although most white women in the study reported that they didn't notice race having an impact on their biking experience, six of the 10 white women in this study did discuss white privilege as 
something that impacted their behaviors, even if they didn't necessarily think about their race every time they rode a bike.

Jade reflected on how racial privilege functions, saying:

People are probably...I am blessed that I have White privilege. So people ...you know, they stop for me if they see me, or treat me better than they might somebody else. Let me get away with more things. Probably cops, too, you know. If they see me not stopping at a stop sign or like doing something illegal, they'll probably not stop me. So I probably can get away with a lot more, being White... [with] White privilege...you don't have to think about a lot of things, or they don't even come up for you that could be issues for other people. So it's easier.

Julia, also a white woman, reflected on white privilege as well when asked about how her racial identity might shape her experience:

Well, I'm White. So the first thing I think about is privilege. And the fact that I'm perceived as White probably means... that I'm afforded more care, regard, right? I imagine that my white skin privilege brings more care and regard from others around me... [things like] access, ability to take up space, the benefit of any doubt, right, all of those kinds of things, at least in a racist society.

These reflections from white women demonstrate the problematic ways that racial inequities can come to seem natural or normal. For women who do not directly experience race-based harassment or discrimination, their mobility may be less restricted in ways they cannot fully realize. While it is heartening to see a number of women able to reflect on their own privilege, there is still a significant challenge in overcoming racial bias in public spaces and within law enforcement. In the previous chapter (3), Carol noted her observation that women have a specific "map" that they use to move through the city that differs from how men might travel; a parallel might be drawn here as we can see that men and women of color might have a different mental map they use to navigate space that is distinct from that of a white person's. These maps are mediated by a person's race, class and gender privilege, making it critical to understand how certain identity markers can alter biking behaviors.

Strategic interventions to address white privilege require additional work at the social and cultural level to educate and increase understanding about how privilege functions. At this critical moment of time in terms of racial politics and racial injustice, those with racial privilege must accept responsibility and work towards speaking out when injustices occur. Robin, a woman of color, spoke about the importance of language in relation to this:

We [have to] address White privilege, and culture of a White supremacy. And that's such a strong word... But unless we say it and we address it, and we know that there's something wrong with that and we know that that hurts everybody, then we're still maintaining the status quo. 


\subsection{WHITE CYCLING CULTURE AND (IN)VISIBILITY OF MINORITIES}

During interviews, all participants were asked what types of things might impact their desire or their ability to bike more. Intertwining themes of visibility and invisibility came up amongst many respondents. On one hand, minority bike riders felt more visible when biking because they infrequently encountered people of color biking. In the biking culture of Portland, which tends to be dominated by white men, minorities often felt very visible. On the other hand, despite feeling more visible on the street, the absence of people of color in signage, advertising or programming related to bikes created a sense of invisibility for minority bike riders.

The two quotes below reflect the sense of increased visibility as a minority experiences:

Velia: I find I'm the only person of color in lots of situations in Portland, but especially in biking. [At some public meetings] I'm the only woman of color there. And that kind of race/ethnic difference is not just biking, but about lots of other things. So if I bring up, referring to a conversation that came up [recently], accessibility issues... whether it's gear or the ability to do longer rides, or just to do things that are bike related are viewed differently if I'm the person that's saying it, as a person of color.

Manuela: I'd say I'm definitely a minority...if we were to go stand out on a street corner, like how many of the cyclists are ethnic? Like, I'm sure we would see a huge gap there. So I guess I'm aware of that... I don't really see a lot of other Hispanic females on bikes... I think it might be a little bit more noticeable that you stand out, as a girl and as a girl of color, for sure.

This increased visibility may make some minorities reluctant to ride more often, and a lack of a diverse cycling culture may create a significant hurdle for minorities who are thinking about picking up a bike for the first time or in thinking about returning to bike riding as an adult.

Simone reflected on the issue of visibility in highlighting that a lack of diverse ridership likely impacted her decisions to bike, and that the value of seeing other bikers of color was very meaningful:

Representation is everything. I tell my kids that, I tell everybody that. It's the same thing like watching T.V. growing up. When I grew up there wasn't any Black people on T.V., not until the Cosby's. Maybe there was a couple of shows, but representation is a big thing, and I think that if people saw more, people of color riding bikes, that would encourage them. And it'd be like, "Oh... I should get a bike.”

Interviewer: But do you think that you personally are affected by that?

I think so. Because I mean, there's been times where I was like, "Oh, I should take my bike?” [But I made a lot of excuses not to]... All of these excuses because I don't see any Black people riding bikes, so why should I ride a bike? And then I started seeing people of color riding... a couple of weeks ago I saw this Black lady and she had her helmet and 
everything... she was going to work, she rode her bike or whatever. Yeah, I think it does, it has affected me a little also... I think a huge part of it is that you don't see it. If you saw it more then you would probably be more open to doing it yourself. Like, "Oh, let me go dust off my bike!”

When it comes to the notion of invisible cyclists, people of color in this research study noted that the lack of representation of minorities in signage and in biking events made it difficult to feel at home as a minority biker in Portland.

Samuel noted how advertisements did not reflect his experience as a cyclist:

You'll see these ads: “Go Green. Bike to work.” White person on the ad... erasing all those people of color who have been biking. All of a sudden it's this new thing? No. Bikes have been Black for centuries, so to make it a new thing by being green then... has that Black person on a bike, have they not been green then?

Ana reported that organizations like the Bicycle Transportation Alliance were not very diverse and were therefore not spaces she would frequent:

I mean BTA does... during bike month or something, they would just be stopped all along Williams [Avenue] with...free drinks and stuff. It's like, I don't want to stop and talk to any of you. You know what I mean... like I still feel like there's not a lot of outreach done to ensure that there's more inclusion in the biking communities. I'm not going to go to any BTA events...I'm just not...I will say I've gone to some of the Sunday parkways...I do appreciate those... and I'm sure BTA is part of that, or whatever... I feel like they make a good effort to make it, like, inclusive and community-driven...[but] I don't feel like Portland is doing really anything to get me to bike.

Marcus reflected on the invisibility of communities of color in relation to urban planning. He spoke at some length about the ways in which gentrification had altered the landscape of his neighborhood to be oriented more around bike infrastructure:

I don't think the city takes into consideration people of color. And the reason I say that is because in our neighborhood, North Williams was a historically Black neighborhood, for a very, very long time. And there was no bike-only lane until gentrification kicked in. And then you saw all these changes happening. And you see this perpetuate throughout the city, you know. As gentrification happens, then you see road changes and bike routes and all these other conveniences happening. Where now, the Black community is being forced out to places like Gresham... [and] you don't see those things. You don't see bike routes, like, being carved into Gresham. You don't see that, you know. And you probably won't see it until there's an influx of young White millennials, you know, that are buying property. You probably won't see that. So, no, I don't think they take that into consideration at all.

Marcus highlights the invisibility that many people of color reported in relation to the city of Portland. Issues of affordability, gentrification and urban planning were discussed by many and 
helped to shed light on how many people of color in this study felt that the cycling culture in Portland was very white and not very inclusive.

During interviews, participants were asked to reflect on how they were, or were not, like the "average" bicyclist in Portland. The composite Portland biker was, for some, a young hipster and for others was a man in spandex, but was overwhelmingly reported to be young, white and male. This perception of who bikes made many participants feel out of place, and many minority participants reported feeling out of place given the racial homogeneity of cyclists in Portland. Carol captured this lack of diversity when she shared this:

This is really awkward, but it's almost that feeling like from high school of wanting to take a computer class or drafting class and not wanting to be the only girl in there. And knowing nothing really bad will happen, but that feeling of like, "Ugh, it's not for me, it's for other people." So I guess that's the public image of cycling, which is more of like a dude with a beard thing. And it's not for other people...that's not a rule written in stone. Anyone can do it, but sometimes it feels that way.

Janae reiterated the feeling of “otherness" in Portland and tied it to historical ongoing issues with racism in Oregon:

... because you're scared. You don't see people that look like you, that can relate to you, and racism is flagrant here in Oregon, we know that. It's one of the third to last states, if I remember correctly, to be desegregated. It's still flagrant. So I'm out trying to be in a community of cyclists that I'm not welcome, wanted, or needed [in]: of course it's going to be a deterrent. That's almost like asking for trouble, if you will.

Ana and Miguel both noted that, as people of color, they are sometimes concerned that their peers will perceive them as trying to act white, illustrating how the perception of cycling as a white person's activity can impact their decision or desire to bike:

Ana: I mean, I definitely was like against learning to bike in the beginning because it felt kind of like a White thing to do...My deepest fear was, like, coming to Portland and becoming a White Portland hipster. I didn't want to be like that. I mean, obviously, I'd never be White. But I didn’t want to be like a White Portland hipster.

Miguel: Well, I think that people are surprised when they see that I bike. I think people get surprised because they're still thinking of it's a thing that White people do, you know?... Even some of my friends from home, Salem, they say like, man, you're doing shit that White people do. And I don't think so, you know. Because, you know, no White person taught me how to ride a bike, you know. But I think it shapes in that way... And I mean the experience of Portland, we're always going to be surrounded by people who does not look like us... on the bus, in the workplace, in the streets, in the bike paths, too. But I think that has to do with my brains, right, that I have to constantly be proving that I'm not biking because I'm doing something that White people do. 
It should also be noted that the whiteness of Portland's cycling culture was reported to extend into bike shops, where many study participants reported feeling unwelcome. Though this experience was highlighted by just a few respondents and was not a specific interview question, it is possible that discrimination in bike shops is a barrier experienced by others. Two quotes from Ana and Marcus highlight this issue:

Marcus: It just, like I said, trying to get service at different bike shops. It's mainly just, like, the attitudes you have to deal with. And I think the assumption is that...you don't know anything about bikes....I think that's the assumption: You're Black. You probably don't know, you know?

Ana: I think, like, in terms of the experience...you don't see yourself often. So it's a little bit like you don't really have that, like ...people of color bike community...I think that there is intimidation, in my experience, of like... around my bike and fixing my bike and knowing all the terminology for all the parts of my bike. Because, you know, for whatever reasons [I feel] like, oh, I don't want to ask. Like I don't feel comfortable here [in a bike shop].

The lack of an inclusive and diverse cycling environment in Portland shaped the experiences of those in this research study. While most people reported that their desire to bike helped them to overcome concerns about their visibility or appearance to others, it should be highlighted that for many people of color in Portland, a lack of diversity in ridership and a lack of events, groups or activities that help to support bikers of color is a significant challenge. Interventions to promote a more inclusive cycling culture might include additional programming and events that are run for, and by, people of color. As Simone noted earlier in this section, "representation is everything," suggesting that signage and advertisements for bike events and organizations should be more diverse. The "bike buddy" program suggested by Robin in the previous chapter on gender might also be an innovative way to encourage people of color to bike more; having a person of color guide new or interested riders might help to alter the perception of biking as a strictly white activity.

\subsection{INTERVENTIONS TO INCREASE RIDERSHIP AMONGST PEOPLE OF COLOR}

In this study, people of color reported a number of barriers to routine cycling. A lack of feeling safe when riding due to aggression in public spaces, a feeling of being both highly visible as a person of color biking (yet feeling simultaneously absent from signs, advertisements and biking events), and broader issues with a lack of diverse bike ridership all contributed to feelings of “otherness” when biking.

Participants overcame many of these obstacles because of their own personal desires to continue to bike, but for many people of color in Portland, these challenges may be significant factors in deterring them to even consider riding a bike. Suggestions to better support minority bicyclists range from social/cultural interventions to challenging and dismantling systems of racial oppression to smaller-scale interventions around representation in signage, access to trainings 
and events tailored for people of color, and more diversity within cycling organizations in Portland.

To close this chapter, a reflection from Samuel can serve to sum up how race can factor into biking as a person of color in Portland:

I don't want to feel that I'm the one sole representative of my race when there's like... we're not just some monolithic being. Man, there's so many personalities, traits, so many colors and shapes, and it sucks sometimes to be seen that way because we don't hold White people accountable the same way. I can't say all White people are like Trump. They're not like that. They're close to that, but again, White people aren't judged like that. As opposed to, again, being a spokesperson for your race and even more so on a bike. I hate it, because you know people are going to take that one negative interaction they had with a person of color and pretty much just project that to all the people of that same race. And that's doing a huge injustice to so many cool people just because you had a negative interaction with another person of color...I don't know. It's heavy at times...

Table 4. 1 Suggested Interventions Related to Race/Ethnicity

\begin{tabular}{|l|}
\hline Reform of police practices and policies; efforts to reduce institutional racism \\
\hline $\begin{array}{l}\text { Increase ridership amongst diverse groups to reduce heightened visibility of minorities; } \\
\text { possibly though a "bike buddy" program }\end{array}$ \\
\hline $\begin{array}{l}\text { Education and training programs that reduce racial bias; naming and calling out white } \\
\text { privilege }\end{array}$ \\
\hline $\begin{array}{l}\text { Increased lighting, signage or protected bike lanes to increase feelings of safety for } \\
\text { minorities deterred from biking due to aggressive driving and cycling behaviors }\end{array}$ \\
\hline More cycling events and organizations run by, and for, people of color \\
\hline Signage and advertisements for bike events and organizations should be more diverse \\
\hline Diverse and inclusive trainings and classes to support interested cyclists \\
\hline
\end{tabular}




\subsection{INTERSECTING IDENTITIES: RACE, CLASS, GENDER, AGE \& ABILITY}

Throughout this study, participants reflected upon the intersections of multiple identities (including, but not limited to, race and gender). Other identity markers such as age, class and ability were discussed in interviews. This section briefly highlights some of the additional barriers to bicycling that are centered on different aspects of identity.

Several women of color from this sample cited race as an overarching oppressive identity, with gender as a second contributor. They often suggested that their experiences on a bike mirrored larger systemic inequalities that they, and other racial minorities, faced every day. Ana, for example, noted how race and gender are linked identities for her:

Talking about intersectionality, we're all these identities. But I definitely feel like my racial identity way more impacts my biking than like my gender identity, even though those two are, you know, so interconnected and linked. I feel more empowered, I think, to bike as a woman than I do as a person of color.

Peter discussed how, because he understood that his status as a black man may already be diminished due to existing racial inequality, riding a bike might not be seen as a positive identity marker for other African-American men:

For Black folks...I think they would prefer to drive a car because it's convenient. It's comfortable...I mean, it's a very deep issue. But even though it is cheaper to have a bike than to have a car. But still I think for the social status, it looks better if you were to have a car rather than a bike... for a Black man who is an adult, riding a bicycle, it's seems...It may give the appearance of childishness. And you know, Black men are very sensitive about their image because of historical content. So, having a bicycle for a Black American, it's very...I mean, I think we have to be very clear that we have to say Black Americans. Because other groups may have different take on that. So...But I think, because of the history in this country, I think for a Black man to ride a bicycle, it may not elevate your social status.

Other participants reflected on similar feelings of uncertainty about how their concerns about public spaces were sometimes about race, sometimes about gender, and often linked to both. For racial minorities, public spaces can frequently feel unsafe, and this feeling may be magnified for women who experience both race and gender oppression. Carla, also a racial minority, articulated her perception of how racial minorities may not regard bikes as having a high social status:

Because it's more than just the economic barrier, there is an economic barrier, but a lot of it's just this cultural idea that you're going to be biking for transportation, and that it's 
cool to bike for transportation. I feel like the few times you see Black kids over the age of eight biking has a very specific image, usually of guys on bikes that are smaller, and it has a very... very hoodlum type image to it instead of it just being someone on a bike getting somewhere. Not that they aren't getting anywhere, I just think it very much has an image.

Many participants also described the economic issues related to cycling that may be a deterrent to more regular cycling behaviors. For many participants the challenge of buying, maintaining and storing a bike was a significant expense. That, coupled with a lack of welcoming bike shops, may make it difficult for many individuals to make the leap into buying their own bike.

Portland's Community Cycling Center completed a 2011 report, "Understanding the Barriers to Bicycling Project," that clearly laid out the economic challenges that many low-income Portlanders face in terms of bike access, maintenance and storage. In the current study, nearly all participants already owned their own bicycle (one participant exclusively used the Biketown bikeshare program). In the present study we still found consistent themes of economic challenges amongst participants.

Rosa discussed the challenge of prioritizing bike repair and maintenance over other expenses:

When I'm not looped into [the college bike shop] network, I'm sort of like...It's happened to me. Oh, my bike isn't working so I'm just going to not do it for a month, because I just don't know what to do. So I think that's been a limitation. So I guess that's kind of my own incompetence, but also kind of about class.

Miguel talked about issues of affordability and cycling gear:

It's more complicated than just, like, a race. But it also has to do with class, right?...I'm thinking about my pants, right? Like, I don't use rain gear not because I don't think I shouldn't. I can't afford it... Same with the helmet...

Janae talked about how families with fixed incomes would have a significant challenge in buying or maintaining a bike:

I don't see any resources for people in poverty, that's what I'd really like to see. People in poverty who can't afford to - oh girl, I get so emotional and so passionate about this! But there's a mother, with a child, $\$ 448$ a month... you can't rent a room for \$448 a month, right? So why would you ever be able to have that experience - you won't. Because you're in survival mode due to the toxic stress of poverty, marginalization, oppression, racism, discrimination, the list goes on and on and on. So if we could get a nonprofit going on where the African-American community could access bikes, especially if they are low income, that would be a start...

Demetrius, the one participant in this study who didn't own a bike and exclusively used the Biketown bikeshare program, talked about how much more he might ride if he owned a bike:

If I had my own bike...But like I said, bikes start at like \$300, \$600. But it's still not something that's accessible when I need to get groceries and I can barely, you know, pay 
rent because I live in this area... with the rent prices rising and me not making that much money...I mean, I make $\$ 14.50$ an hour, which is...It's a good amount for, like, how much bills I have to pay. But it's, like, not enough to have a super lot of expendable money to just be like, oh, I'm going to buy a bike. That's a commitment for me that I need to make.

Ana summed up the intersection of multiple identities in saying:

And also, like yes, having a bike does end up saving you a lot of money. But it's also, like, still hella expensive, getting your bike, taking care of your bike, knowing how to take care of your bike. I wouldn't know shit about taking care of my bike had [husband] not taught me. You know what I mean? Like to actually learn how to like care for it and clean it and replace parts and know when it's not working. I mean all of those things, I think, require quite a bit of privilege and accessibility to learn how to do all those things. And so I think those are some reasons.

In terms of additional barriers to biking related to one's identity, some participants reflected on challenges related to ability and physicality. For some cyclists, the size of their body gave them an additional set of concerns to think about or consider when biking.

Demetrius: Like I said, my size is, I feel like, one of them I worry about. When bikes come past me, I try to squeeze myself together to make myself feel smaller or to appear smaller or to be smaller so that the people can get by. And like I said, people judging me, oh, this fat kid is on a bike or something like that, I'm like, oh okay, whatever. But I don't know why people judge fat people doing exercise because it seems like if you want them to be skinny, that's the way to do it. But...

Julia: That said, I'm also...I'm fat. And I deal with chronic pain. Both of those things combine to make cycling almost always at least a little bit uncomfortable to me. Either uncomfortable because I'm worried about perceptions that others have of me or my body, or I'm in pain. And, you know, that's clearly uncomfortable.

Though no participants in this study used anything other than a bicycle, it should be recognized that issues of body size and disability might be at odds with the type of infrastructure available. Narrow bike lanes may limit the comfort and safety of larger riders, or may deter those using other types of cycles (e.g., hand cycles, recumbent bicycles).

Finally, though most participants in this study were under the age of 65, age and ability may be a factor in people's willingness or ability to bike. No one in the current study said that their age hampered their ability to bike, but Robin clarified how different life stages may mean different types of biking behaviors are practiced. Ideally, there would be infrastructure and support for all age groups:

For a long time, I was a stay-at-home mom. And I'm going to bike differently when I have kids and I need to go to the store and the library and the museum. You're biking differently at different stages of your life as a woman. You know, your childbearing years 
versus your...You know, like, I'm middle-aged years. I don't have to drive my kids around everywhere. So, you know, that recognition that our lives change and the demands on our time change, there's got to be some...that's got to be considered, right, that we...You know, there's pre-kid days, totally different story than during your kid days, during your menopause days or during your time when your teenagers are growing up and you're, like, I don't have to rush home. I can take the long route home. So there's something there, too.

This section is not meant to be an exhaustive accounting of all of the ways that one's identity may shape or limit cycling behaviors, but it is intended to be a jumping-off point for better understanding how a range of vulnerabilities across multiple different dimensions of identity may act to discourage routine cycling. Strategic interventions in the previous two chapters should be considered in relation to the intersections of identity. Additional research being done in support of inclusive cycling for all types of mobility would also be vital in better understanding how to support cyclists with disabilities. ${ }^{10}$

${ }^{10}$ Wheels for Wellbeing, an organization in the UK, has resources on this:

http://www.wheelsforwellbeing.org.uk/inclusive-cycling/ 


\subsection{CONCLUSION: PROMOTONG ROUTINE CYCLING FOR WOMEN AND MINORITIES}

This report has highlighted the various mechanisms that can deter women and minorities from engaging in more routine cycling behaviors. As this study is qualitative, it is not generalizable however, these narratives can be used to help better understand how gender and racial oppression may contribute to lower rates of cycling amongst women and minorities in Portland.

Given the consistent pattern of fear, anxiety and stress that women and minorities reported encountering when navigating public spaces, additional support must be given to cultivate and maintain a diverse biking population. Interventions that create opportunities for women and people of color to be integrated into local cycling organizations, and which allow for representation in all of the various spaces in which biking occurs (bike shops, volunteer organizations, events, advertisements), is critical to increasing cycling amongst these groups.

This report concludes with brief insights into the reasons why, despite the challenges discussed in previous chapters, people still choose to bike. The chapter also concludes with a chart that summarizes the interventions discussed throughout the report.

\subsection{SO WHY BIKE? EMPOWERMENT AND FREEDOM}

Despite many gendered challenges to cycling reported by women, some participants were able to find positivity in their visibility on a bike. Women reported feeling empowered by moving their bodies in particular ways, defying certain stereotypes, or in being able to move through spaces in ways that felt different, safer, and physically challenging in important ways.

Julia spoke about her struggles as an overweight cyclist, and finding her bike as a tool to challenge mainstream perceptions of women's bodies:

I hate to make everything about fat... [but] there is something about being willing to get on a bike in my body, in my gender, that is a cool thing... there's just something about being visible, because you're really visible on a bike in a way that you're not in a car, right? And so there's something about that visibility that I think is pretty cool.

Rosa indicated that she enjoyed biking for the enhanced ability it gives her to avoid unwelcome advances:

...I feel like I'm less available for people to talk to me. All of my weird experiences have been waiting for the bus or being on the bus...This just happened this week, where [this 70-year-old man on the bus says to me] like, "I am picturing the two of us in those two seats at the movies.” ...that never happens on a bike, you know, because they literally can't talk to you because you are moving. So that's actually something I've liked more.

Freedom to avoid unwanted interactions was a sentiment echoed by Carla, who reported that riding a bike gave her the feeling that she would be in a position to quickly exit an unsafe 
situation. In contrast to some women's sentiments noted above, Carla reported seeing her bike as a source of strength:

I would say bikes actually give me more freedom. Some of that might be fake freedom, because it's not like some car couldn't hit you ... but I do feel like if you're worried at night...worried [about] walking the pace you're walking, or running away from somebody - [that] fear that most women carry around by being out late at night - I just feel a lot safer... as long as I'm moving on my bike it'd be really hard for somebody to attack me. Even if I was at a stoplight late at night, I could just go ahead and run it if I really felt that way, so I would probably say, I feel like it gives me more freedom to move than I would if I were walking.

A number of riders discussed the ways that biking was important to them for the enhanced ability to move through space and to experience the city in a different way:

Peter: When I bike I like to see what people are up to. I like people. I like watching people. So as I bike I just like to observe the scenery. So, I mean, I like the feeling of biking because it gives you a lot of control. It gives you a good sense of independence. So I love that a lot... so that's why I really don't like driving because it takes away from that independence.

Aneisha: I'm fascinated because what I love about it is that you see neighborhood, when I see cyclists and as a cyclist, I love that I can see a neighborhood completely different than as a driver. So I could have driven that neighborhood twenty times, and when you are on a bicycle you see it very differently.

Samuel: It's good to feel the crisp air on your face sometimes, and it's a good way to decompress honestly. I prefer to ride during the day but I do ride at night sometimes. I don't know, you just ride faster to get to your destination because... again, it's exhilarating, just this adrenaline rush like... Oh man, you're not constricted to the driving lanes, like, “Oh, what's down that street? I don't know but I'm going to go find out because I'm on a bike and I can make a turn so easily.”

All of the cyclists in this study reported some sort of positive experience that revolved around the freedom of movement in public spaces or the community they enjoyed when biking with friends or family. For many individuals, the benefits of biking could outweigh some of the challenges, fears and concerns they reported.

On the following page is a summary of all of the interventions discussed in this report. Some of the suggestions are complex and relate to structural and institutional forms of oppression. Other solutions are smaller and more easily implemented. Solutions to build a diverse cycling community in Portland will require both large- and small-scale interventions. Given the routine experiences of racial and gender oppression discussed in this report, it is critical to work at both the large and small scale; to do one without the other misses the mark. Building an inclusive cycling culture requires strategic movement to support new and diverse ridership, but also requires naming, addressing and working to reduce racism, sexism and homophobia in all its forms. 
In closing, the following quote from Tara, offers beautiful imagery for what this cycling future might look like:

...And for the most ideal bike ride ever: My daughter would be gone for some reason, maybe sleeping at her friend's or moved out. And I'm all by myself, and I wake up and now that she's gone, I don't have to be all controlling and meticulous, and I can just go to Voodoo Donuts or something...so I'll just ride up to Sandy and it'll be sunny but a little overcast so that there's not sun in my eyes, or making me hot, and then a nice cold breeze... I'll go down Sandy to Voodoo Donuts...the one on Sandy....and I have the bike lane on Sandy and no cars almost hit me, no cars yell at me, no guys say "Hey, baby," and there's no other bikers telling me that I'm too slow, and I see on this side of the street a whole bunch of other bikers, like maybe a Mexican lady, a Black lady, a Chinese guy, a Pacific Islander chick, you know, a whole bunch of - and a white guy in there, so all different types of people. And then I see in front of me, there's a family maybe, like a dad and a mom and little kids. And the dad is in the very back, the mom is in the front, and the kids are in the middle, and then to avoid them I'll "Pyoom!" up on the sidewalk and I'll go in front. And they'll honk their little horn or something cute. And then I'll go further down and I'll go to Voodoo Donuts and there is no line, and I'll have my donut, and I'll go home with the same exact stuff happening. That's the best. 


\section{Table 6.1: Suggested Interventions}

\begin{tabular}{|c|c|c|}
\hline $\begin{array}{l}\text { Major } \\
\text { Themes }\end{array}$ & Sub-Themes & Suggested Intervention \\
\hline \multicolumn{3}{|l|}{ Gender } \\
\hline & Safety & Increased lighting and wayfinding, inclusion of more protected lanes \\
\hline & $\begin{array}{l}\text { Increased Visibility } \\
\text { \& Harassment }\end{array}$ & $\begin{array}{l}\text { Women’s group rides; “bike buddy” programs to support riders or additional women’s biking groups; } \\
\text { bystander invention training }\end{array}$ \\
\hline & Appearance & Increased availability of bike lockers, showers \\
\hline & Parenting & $\begin{array}{l}\text { Events to support families; trainings or classes about utility bikes and adapting bikes for carrying heavier } \\
\text { loads; infrastructure adaptations that meet the needs of utility bikes or trailers }\end{array}$ \\
\hline \multicolumn{3}{|l|}{ Race } \\
\hline & $\begin{array}{l}\text { Racism \& Racial } \\
\text { Profiling }\end{array}$ & Reform of police practices and policies; efforts to reduce institutional racism \\
\hline & $\begin{array}{l}\text { Invisibility of } \\
\text { People of Color }\end{array}$ & $\begin{array}{l}\text { Increase ridership amongst diverse groups to reduce heightened visibility of minorities; possibly though a } \\
\text { "bike buddy" program; increased lighting, signage or protected bike lanes to increase feelings of safety } \\
\text { for minorities deterred from biking due to aggressive driving and cycling behaviors; more cycling events } \\
\text { and organizations run by, and for, people of color; signage and advertisements for bike events and } \\
\text { organizations should be more diverse }\end{array}$ \\
\hline & $\begin{array}{l}\text { White Bike Culture } \\
\text { and Discrimination } \\
\text { in Bike Shops }\end{array}$ & $\begin{array}{l}\text { Education and training programs that reduce racial bias; naming and calling out white privilege; diverse } \\
\text { and inclusive trainings and classes to support interested cyclists }\end{array}$ \\
\hline $\begin{array}{l}\text { Intersecting } \\
\text { Identities: } \\
\text { Class, } \\
\text { Ability }\end{array}$ & & $\begin{array}{l}\text { Additional programming to support the needs of low-income individuals; additional training or } \\
\text { information on repairing and maintaining a bicycle; increased access to low-cost bikeshare memberships; } \\
\text { additional consideration about infrastructure needs of persons with disabilities who may ride alternative } \\
\text { types of cycles }\end{array}$ \\
\hline
\end{tabular}




\subsection{REFERENCES}

Aldred, Rachel, James Woodcock and Anna Goodman. 2015. “Does More Cycling Mean More Diversity in Cycling?” Transport Reviews DOI:10.1080/01441647.2015.1014451

Bogdan, Robert and Sari Knoop Biklen. 2007. Qualitative Research for Education. Boston: Allyn and Bacon.

Bopp, Melissa, Stephanie Child, and Matthew Campbell. 2014. "Factors Associated with Active Commuting to Work Among Women.” Women \& Health 54(3): 212-231.

Buehler, Ralph. 2012. "Determinants of bicycle commuting in the Washington, DC region: The role of bicycle parking, cyclist showers, and free car parking at work.” Transportation Research Part D: Transport and Environment 17(7): 525-531.

Buehler, Ralph and John Pucher. 2012. “International Overview: Cycling Trends in Western Europe, North America, and Australia. In: John Pucher and Ralph Buehler (Editors), City Cycling. MIT Press, Cambridge, MA.

Community Cycling Center. 2012. Understanding the Barriers to Bicyling Final Report. Portland, OR.

Dill, Jennifer and Kim Voros. 2007. "Factors Affecting Bicycling Demand: Initial Survey Findings from the Portland, Oregon, Region.” Transportation Research Record: Journal of the Transportation Research Board 2031: 9-17.

Dill, Jennifer and Nathan McNeil. 2013. "Four Types of Cyclists? Examination of Typology for Better Understanding of Bicycling Behavior and Potential.” Transportation Research Record: Journal of the Transportation Research Board 2387: 129-38.

Emond, Catherine, Wei Tang, and Susan Handy. 2009. "Explaining gender difference in bicycling behavior.” Transportation Research Record 2125(1): 16-25.

Garrard, Jan, Chris Rissel, and Adrian Bauman. 2012. “Health Benefits of Cycling.” In: John Pucher and Ralph Buehler (Editors), City Cycling. MIT Press, Cambridge, MA.

Garrard, Jan, Susan Handy, and Jennifer Dill. 2012. "Women and Cycling.” In: John Pucher and Ralph Buehler (Editors), City Cycling. MIT Press, Cambridge, MA.

Garrard, Jan, Geoffrey Rose, and Sing Kai Lo. 2008. "Promoting transportation cycling for women: The role of bicycle infrastructure.” Preventive Medicine 46 (1): 55 - 59. 
Glaser, Barney and Anslem Strauss. 1967. The Discovery of Grounded Theory Strategies For Qualitative Research. Chicago: Aldine.

Goddard, Tara, Kimberly Barsamian Kahn and Arlie Adkins. 2014. "Racial Bias in Driver Yielding Behavior at Crosswalks". NITC-SS-733. Portland, OR: Transportation Research and Education Center (TREC), http://dx.doi.org/10.15760/trec.130

Huy, C., S. Becker, U. Gomolinksky, T. Klein, and A. Thiel. 2008. "Health, Medical Risk Facors, and Bicycle Use in Everyday Life in Over-50 Population.” Journal of Aging and Phyical Activity 16 (4): 454-65.

Law, Robin. 1999. "Beyond 'Women and Transport': towards new geographies of gender and daily mobility.” Progress in Human Geography 23(4): 567-88.

Litman, Todd and Eric Doherty. 2009. "Transportation cost and benefit analysis: techniques, estimates and implications.” (2nd ed). Victoria Transport Policy Institute.

McKenzie, Brian. 2013. "Neighborhood Access to Transit by Race, Ethnicity, and Poverty in Portland, OR.” City \& Community 12: 134-155.

Oja, Pekka, Sylvia Titze, Adrian Bauman, Bas de Geus, P. Krenn, B. Reger-Nash, and T. Kohlberger. 2011. "Health benefits of cycling: a systematic review." Scandinavian Journal of Medicine \& Science in Sports 21: 496-509.

Pucher, John, Ralph Buehler, and Mark Seinen. 2011. "Bicycling renaissance in North America? An update and re-appraisal of cycling trends and policies.” Transportation Research Part A 45: 451-475.

Pucher, John, Jennifer Dill and Susan Handy. 2010. "Infrastructure, programs, and policies to increase bicycling: An international review.” Preventive Medicine 50 (Suppl. 1): S106-S125.

Scheider, Kate. 2010. Bicycle Leadership Conference Demographics Survey Report. Boulder, CO: Bikes Belong Coalition.

Steinbach, Rebecca, Judith Green, Jessica Datta, and Phil Edwards. 2011. "Cycling and the city: a case study of how gendered, ethnic and class identities can shape healthy transport choices." Social Science \& Medicine 72(7): 1123-1130.

Strauss, Anselm and Juliet Corbin. 1990. Basics of Qualitative Research. Newbury Park, CA: Sage.

Tran, Marc. 2015. "Combatting gender privilege and recognizing a woman's right to privacy in public spaces: Arguments to criminalize catcalling and creepshots.” Hastings Women's Law 26: 185-206.

Tuerkheimer, Deborah. 1997. Street Harassment as Sexual Subordination: The Phenomenology 
of Gender Specific Harm, 12 Wisconsin Women’s Law Journal 12 (2): 167-206.

Vidu, A., Valls, R., Puigvert, L., Melgar, P., \& Joanpere, M. 2017. Second Order of Sexual Harassment - SOSH. Multidisciplinary Journal of Educational Research, Online First, 1-26. doi:10.17583/remie.2017.2505

Wen, Li Ming, and Chris Rissel. 2008. "Inverse associations between cycling to work, public transport, and overweight and obesity: findings from a population based study in Australia.” Preventative Medicine 46: 29-32. 



\subsection{APPENDIX}

\subsection{INTERVIEW GUIDE}

\section{Introduction}

- How long have you lived in Portland?

o If you moved here recently — what brought them to Portland?

- What part of the city do you live in?

- What's your favorite thing about living in this city?

- Can you walk me through a typical day in your life? What do you do and where do you go?

o What types of transportation do you use? Does it change between weekday and weekend?

\section{Biking Behavior}

- What kind of bike do you have? Where do you store your bike?

o Do you have bike accessories?

- Describe an average or typical bike riding experience for you

o How do you think your experience compares to the average Portland cyclist?

(Whatever you think the average Portland cyclist is? What do they look like?)

o What kind of clothes do you wear while biking? (Raingear, casual, etc.)?

- Besides the typical ride you described, what are some other places you might go (or have gone) on your bike?

- Do you ride bikes with people? If so, how often, and who?

- Is there a particular time of day that you prefer to ride?

o When do you avoid riding? Do you ride at night?

- Do you feel safe while cycling?

- Do you bike with your family or children?

- How does the weather impact your riding habits?

Experiences:

- What makes riding your bike a positive experience for you? Do you have a specific memory?

o Prompt: Who was present? Time of day? Feelings/specifics that made it positive?

- What makes riding your bike a negative experience for you? Do you have a specific memory?

o Who was present? Time of day? Feelings/specifics that made it negative?

- How do you feel other cyclists and pedestrians affect your experience?

o How do you interact with them if you do? Positive or negatively?

- How do you feel your gender shapes your experiences when you are biking?

0 What are the positives/benefits of your gender in cycling in Portland?

o What are the negatives/disadvantages of your gender in cycling in Portland?

- How do you feel your race shapes your experiences when you are on your bike?

o What are the positives/benefits of your race in cycling in Portland?

o What are the negatives/disadvantages of your race in cycling in Portland? 
- Are there any other individual traits you feel affect your cycling experiences?

o (follow up on other parts of their identity they might have mentioned-class, sexuality, disability/injuries, body)

\section{Barriers}

- What prevents you from biking more?

o Prompt: is it an equipment issue, a social issue, an infrastructure, or other?)

- Would you like to ride more?

o Since you said that you would like to bike more: what would help you do so?

o Since you said you would not like to bike more: what would make you want to bike more?

- What is your ideal cycling situation?

- How does being in Portland shape your cycling experience?

o Does the city of Portland do anything to help people like you bike more? Should it do something else?

- Is there anything else that you would like to tell me? 
Transportation Research and Education Center

Portland State University

1900 S.W. Fourth Ave., Suite 175

Portland, OR 97201 